\title{
Performance of Diesel Engine Fueled with Biodiesel (Coconut Oil and Cotton Seed Oil Blended With Diesel) and Analysis of Combustion Products
}

\author{
S. Nagendra, A.V.N.S. Kiran, D. Swetha, \\ S.M. Saleemuddin \\ Assistant Professor, Department of Mechanical Engineering, Annamacharya Institute of Technology and \\ Science, Rajampet, Kadapa Dist. INDIA.
}

\begin{abstract}
The world is facing crisis due to the dwindling sources of fossil fuels. Rapid depletion of conventional energy is a matter of serious concern for the mankind. There is a necessity to find alternative fuels for different industrial needs, automobiles and aircrafts. The conventional forms of energy supply and consumption are causing serious economical as well as environmental problems. Import dependence for oil in India is about 70 percent, and is likely to increase further. If the fossil fuels are consumed at present rate it may not take much time before the oil reserves get totally exhausted. It is, therefore, imperative to search for the alternative fuels that are renewable in nature, locally grown and friendly to environmlent. Diesel and alternative fuels like coconut oil and cotton seed oil are used as fuels. Previously efficiency of alternative fuels like coconut oil and cotton seed oil blends with diesel was tested. The blends of varying proportions of these alternative fuels and diesel are used to run the engine and significant improvements in engine performance and emission characteristics are observed.These improvements are attributed to more complete combustion of oxygenated fuel. Engine performance values such as Indicated Horse Power, Brake Horse Power, Fuel Consumption, Mechanical Efficiency, Volumetric Efficiency, Indicated Brake Thermal Efficiency and Air Fuel Ratios are determined by varying fuel injection pressure with variation of Engine loads along with different blends of oils. Even through the viscosity of the coconut oil is low and is economically friendly. Considering the thermal efficiency, the cotton seed oil blend (B50) is preferable as it is giving it is good characteristics curve.
\end{abstract}

\section{Introduction}

In recent times, the world has been confronted with the energy crisis due to depletion of natural resources and increased environmental problems. The situation has led to the search for an alternative fuel, which should be not only sustainable but also environment friendly. For developing countries, fuels of biorigin, such as alcohol, vegetable oils, biomass, biogas, synthetic fuels, etc. are becoming important. Such fuels can be used directly, while others need some sort of modification before they are substituted for conventional fuels. With an expected growth rate of diesel consumption of more than $14 \%$ per annum, shrinking crude oil reserves and limited refining capacity, India will have to depend heavily on imports of crude. From the point of view of protecting the global environment and the concern for long-term supplies of conventional diesel fuels, it becomes necessary to develop alternative fuels comparable with conventional fuels. Diesel fuel is largely utilized in the transport, agriculture, commercial, domestic, and industrial sectors for the generation of power and the substitution of even a small fraction of total consumption by alternative fuels will have a significant impact on the economy and the environment. Of the alternative fuels, biodiesel obtained from vegetable oils holds good promise as an eco-friendly alternative to diesel fuel. The petroleum industries were able to make inroads in fuel markets because their fuel was much cheaper to produce than biomass alternatives at that time. The result for many years was a near elimination of the biomass fuel production infrastructure. But the supply of petroleum derive diesel fuel is limited. The depletion in world petroleum reserves and uncertainty in petroleum supply due to political and economical reasons stimulated the search again alternative sources for petroleum based fuels especially for diesel fuels.

The research was conducted in various universities and research organizations by OPEC (Organization of Petroleum Exporting Countries). The general conclusion is that biodiesel is technically acceptable blending stock for conventional petroleum diesel. In 1979 the Transesterification of vegetable oil and refining it to diesel standards was initiated in South Africa. In 1989 the first industrial scale plant is established in Austria. Throughout the 1990's plants were opened in many European countries. Throughout the 2000's number of plants were opened worldwide. 


\section{Literature Review}

Mr.S.V.Channapattana Dr.R.R.Kulkarni [1]:

The rapidly increasing consumption of fossil fuel and petroleum products has been a matter of concern for the many countries which imports more crude oil. Because it causes huge foreign exchange out-go on the one hand and increasing exhaust emission on the other. Therefore it is necessary for the development of renewable energy sources. Vegetable oils have become more attractive recently because of their environmental benefits and it is made from renewable resources. Bio-diesel commands crucial advantages such as technical feasibility of blending in any ratio with petroleum diesel fuel, use of existing storage facility and infrastructure, superiority from the environment and emission reduction angle, its capacity to provide energy security to remote and rural areas and employment generation. There are more than 350oil bearing crops identified, among which only sun flower, sunflower, soybean, cottonseed, rapeseed, Jatropha cruces and peanut oils are considered as potential alternative fuels for Diesel engines. So a particular crop which is available in surplus within the country should be used to produce Bio-diesel. This paper reviews the extraction and properties of Bio-diesel, also the outcomes of the research work done in different countries. Also efforts have been made to include the Bio-diesel scenario in India.

\section{R. Ganapathi, Dr. B. Durga Prasad, B.Omprakash[2]:}

Increasing industrialization, growing energy demand, limited reserves of the fossil fuels and increasing environmental pollution have jointly necessitated for exploration of some substitute of conventional liquid fuels. Vegetable oils had been considered as one of the appropriate feasible substitute diesel fuel since very early. The vegetable oil based substitute fuels, popularly known as biodiesel, are commercially available in the developed world due to their distinct advantages over conventional diesel fuel. Vegetable oils present very promising alternative fuels to diesel. Properties of these oils compare favourably with characteristics required for C.I.engine fuels. The usage of vegetable oil in an engine depends on the properties of the oil. Jatropha oil properties are almost closer to diesel, particularly cetane rating and heat values. These oils are renewable and are produced easily in rural and forest areas An objective of this work aims to find out suitability of Jatropha oil in an insulated engine. An Air gap liner and PSZ coated head and valves have been used in the present study. Experimental investigations have been carried out to assess the suitability of Jatropha oil as C.I. Engine fuel. Experiments were conducted on the base engine and also in an insulated engine. A solemn attempt has been made in this research to study the usage of Bio-diesel of Jatropha oil in place of diesel so as to study the engine performance.

Dhruva D,Dr. M C Math [3]:

In this paper characteristic fuel properties of crude rice bran oil methyl ester((RBOME) and its blends with conventional diesel oil in the proportions of 20:80(B20), 40:60(B40), 60:40(B60), 80:20(B80) and 100:0(B100) respectively were studied. Rice bran oil methyl ester was prepared from crude rice bran oil by using three stage transesterification processes. In the first two stages, $\mathrm{H} 2 \mathrm{SO} 4$ was used as an acid catalyst to reduce the free fatty acid (FFA) level to less than $1 \%$. In the third stage, $\mathrm{NaOH}$ was used as an alkaline catalyst to complete the transesterification reaction with methanol. Fuel properties such as viscosity, gross calorific value, flash and fire points were compared with conventional diesel oil to study their usefulness as compression ignition fuel. The characteristics fuel properties of RBOME blends were found to deviate more from those of diesel oil with the increasing in the percentage of methyl ester in the blend. It was also found that the properties of blend of B20 were found very close to those of conventional diesel oil. In addition, an attempt has made to reduce diesel proportion in blends by adding domestic kerosene in the proportions (methyl ester: conventional diesel: kerosene) of 20:75:5, 40:50:10, 60:25:15 and 80:0:20 respectively were studied.

\section{AlirezaValipour [4]:}

The effect of cylinder air pressure with different injection pressure on combustion characteristics of biodiesel blended with diesel fuel in Direct Injection (DI) diesel engine with hot surface ignition was investigated. Experiments were carried out in a constant volume combustion chamber under conditions similar to the real engine condition using a single holepintle nozzle. The present study analyzed the combustion characteristics of $20 \%$ and $40 \%$ blending of Jatropha Methyl Ester (JME) with diesel as fuels in diesel engine. The combustion characteristics such as ignition delay, combustion duration and duration of injection were computed. The injection pressure range chosen was 100 to 300 bar with variation of ambient air pressure from 5 to 25 bar. The results showed that for all test fuels the reduction in ignition delay increases with the increase in injection pressure and ambient air pressure. The jatropha biodiesel (JBD) higher cetane number, facilitated shortest ignition delay when compared to the diesel fuel under all injection pressures and ambient air pressure. It was seen that, the combustion durations of JBD20 were slightly more than diesel fuel, but with the increase in 
the amount of biodiesel in the blend, combustion duration increased for JBD40 which may be due to increase in amount of fuel injected but with the increase in injection pressure from 100 to 300 bar leads to reduction in combustion duration. It was clear that the injection duration of diesel fuel is higher than JBD.

McGill, R., Storey, J., Wagner, R., Irick, D. et a [5]:

Because of the great interest in biodiesel fuels around the world, the International Energy Agency's Committee on Advanced Motor Fuels sponsored this project to determine emissions and performance of a number of biodiesel fuels with a special emphasis on unregulated emissions. Oak Ridge National Laboratory (ORNL) and Technical Research Centre in Finland (VTT) carried out the project with complementary work plans. Several different engines were used between the two sites, and in some cases emissions control catalysts were used, both at ORNL and at VTT. ORNL concentrated on light and medium duty engines, while VTT emphasized a heavy-duty engine and also used a light duty car as a test bed. Common fuels between the two sites for these tests were rape methyl ester in $30 \%$ blend and neat, soy methyl ester in 30\% blend and neat, used vegetable oil methyl ester (UVOME) in $30 \%$ blend, and the Swedish environmental class 1 reformulated diesel (RFD). ORNL used ASTM 2D diesel as baseline, while VTT used EN 590 (European diesel) as the base. VTT also tested a blend of 30\% UVOME with RFD. Steady state test cycles were used for all engines and fuels except for the light duty vehicle, which was tested on a chassis dynamometer using the US FTP 75 test. Results are presented for regulated emissions as well as for aldehydes and composition of particulate matter, and polyaromatic hydrocarbons. VTT also produced results of Ames tests on the mutagenicty of samples of particulate matter. Generally, the biodiesel fuels had higher NOx emissions but lower values of HC, CO, and particulates. Unregulated emissions varied greatly between fuels and engines.

Postrioti, L., Battistoni, M., Grimaldi, C., and Millo, F. [6]:

The potentialities in terms of engine performance and emissions reduction of pure biodiesel were examined on a Common Rail HSDI Diesel engine, trying to define a proper tuning of the injection strategies to bio-fuel characteristics. An experimental investigation was therefore carried out on a typical European passenger car Diesel engine, fuelled with a soybean oil derived biodiesel. A standard European diesel fuel was also used as a reference. In particular, the effects of an equal relative air/fuel ratio at full load condition were analyzed; further, a sensitivity study on the outcome of the pilot injection timing and duration at part load on engine emissions was performed. Potentialities in recovering the performance gap between fossil fuel and biodiesel and in reducing NOx specific emissions, affecting only to a limited extent the biodiesel emission benefit in terms of $\mathrm{CO}, \mathrm{HC}$ and FSN, were highlighted.

Vellguth, G.[7]:

Vegetable oils have the potential to be used as fuels for diesel engines. But in direct injection engines as they are used for agricultural tractors and trucks some difficulties with vegetable oils - even with fully refined oils -are noticed, so that long time operation is impossible. Enginetests were made to evaluate some modifications to these oils. The result is that the former problems do not occur with derivates of vegetable oils after transesterification with ethanol or methanol, if the injection is advanced. Over 30 different vegetable oils have been used to operate compression ignition engines since the 1900's. Initial engine performance suggests that these oil-based fuels have great potential as fuel substitutes. Extended operation indicated that carbonization of critical engine components resulted from the use of raw vegetable oil fuels, which can lead to premature engine failure. Blending vegetable oil with diesel fuel was found to be a method to reduce coking and extended engine life.

\section{Experimental Setup}

A single cylinder 4-stroke water-cooled diesel engine having $5 \mathrm{HP}$ as rated power at $1500 \mathrm{rpm}$ was used for the research work. The engine was coupled to an electrical dynamometer for loading it. A photo sensor along with a digital rpm indicator was used to measure the speed of the engine. The fuel flow rate was measured on volumetric basis using burette and a stopwatch. Thermocouples in conjunction with a digital temperature indicator were used for measuring the engine and exhaust gas temperatures. A digital data acquisition system in conjunction with a piezoelectric transducer was used for the measurement of cylinder pressure data. 


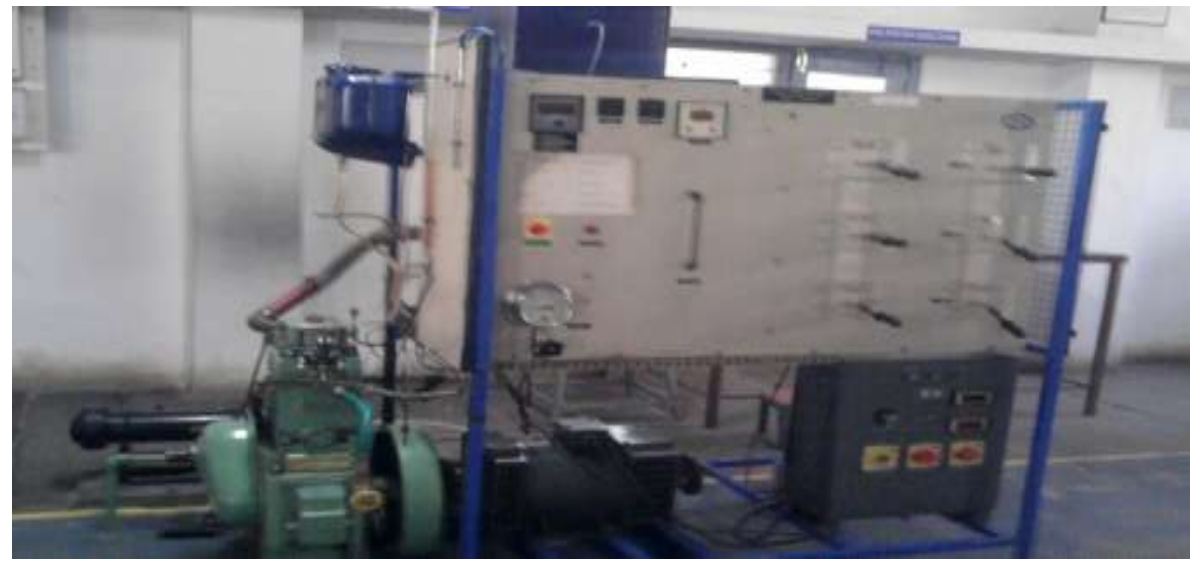

Fig.1 Experimental Setup

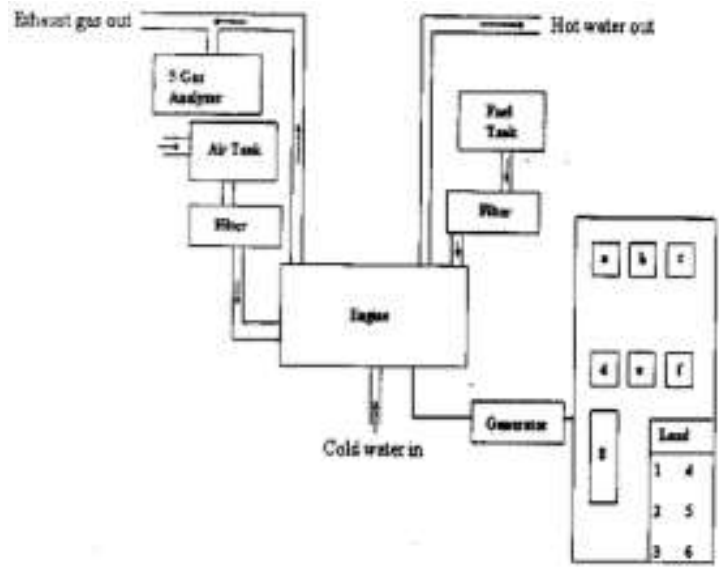

Fig.2 overview of experimental setup

$\begin{array}{ll}\text { Engine } & : \text { Kirloskar diesel } \\ \text { Coefficient of discharge } & : 0.65 \\ \text { Injection timing } & : 28^{\circ} \mathrm{BTDC} \\ \text { Compression ratio } & : 16.5: 1 \\ \text { Orifice diameter } & : 20 \mathrm{~mm} \\ \text { Maximum H.P } & : 5 \mathrm{H} . \mathrm{P} \\ \text { Stroke } & : 110 \mathrm{~mm} \\ \text { Bore } & : 80 \mathrm{~mm} \\ \text { Type } & : \text { Water Cooled } \\ \text { Maximum load of engine } & : 20.45 \text { amps }\end{array}$

\section{Experimental Procedure}

1) After carefully going through the preliminaries the decompression lever is pressed on so that there will not be any air trapping in between the cylinder head and piston.

2) Then the engine is started by rotating the crank by means of hand crank lever by throwing of the decompression lever at sufficient speed.

3) The engine is allowed and adjusted to pick up the speed and run at rated speed, smoothly for few seconds at rated speed using the tachometer.

4) Record the time taken for $20 \mathrm{cc}$ fuel consumption at no load and the manometer reading on the panel board.

5) Then the engine is loaded by slowly lowering the copper plate in the water rheostat, and care should be taken to see that the voltage developed should be always at 220/230 volts by adjusting the field current.

6) After setting the load on the engine at fixed point the time required for $10 \mathrm{cc}$ of fuel is measured and also the difference of manometer reading on the panel board.

7) The pollution values are recorded from Automotive Emission Analyzer setup. 
The same procedure repeated for the oil blends of $25 \%, 50 \%$ and $75 \%$ of coconut oil with diesel and also for the same proportion of cotton seed oil.

\section{Results And Discussions}

Experiments have been performed, experimental data have been obtained, investigated and analysed for a single cylinder 4-stroke, 5HP diesel engine using coconut, diesel and cotton seed oil at different blends. Calculations of engine performance and exhaust emission are derived in order to obtain the statistical differences between coconut, diesel and cotton seed oil by using different blends. Most of the discussions emphasize on the comparison of exhaust emissions and engine performance for coconut, diesel and cotton seed oil by using different blends at minimum and maximum load condition at average speed (rpm) of the engine. During continuous running of a single cylinder 4-stroke, 5HP diesel engine for given time period, the mass flow rate of fuel, air flow rate for lambda (for getting engine performance), speed and oil temperature of engine, exhaust gases such as $\mathrm{NO}_{\mathrm{X}}, \mathrm{CO}_{2}, \mathrm{CO}$, and $\mathrm{HC}$ are studied and through which emission characteristics and overall performance of the engine has been shown. The variation of results appeared is according to load operations and type of fuel used. The content of $\mathrm{NO}_{\mathrm{X}}$ and $\mathrm{HC}$ emissions are measured in parts per million (ppm) while the contents of $\mathrm{CO}_{2}$ and $\mathrm{CO}$ emissions are measured in terms of percentage vol. The experiments were performed at ambient condition.

\subsubsection{Absolute Viscosity}

\section{Fuel Characteristics}

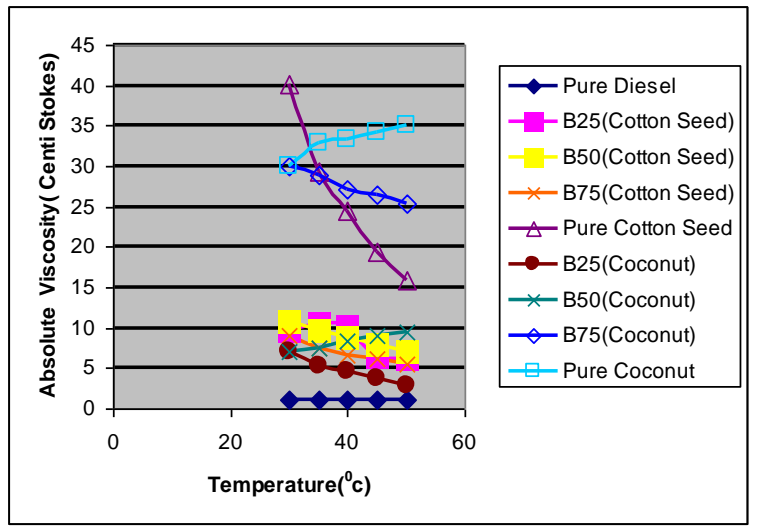

Fig. 5.1. Temperature Vs Absolute Viscosity

The variation of absolute viscosity with temperature for diesel and other fuels with blends are shown in Fig. 5.1. As temperature increases, absolute viscosity decrease and it is due to reduction in molecular attraction force. At all temperature pure coconut oil has more absolute viscosity compared other fuels and different blends.

\subsubsection{Kinematic Viscosity}

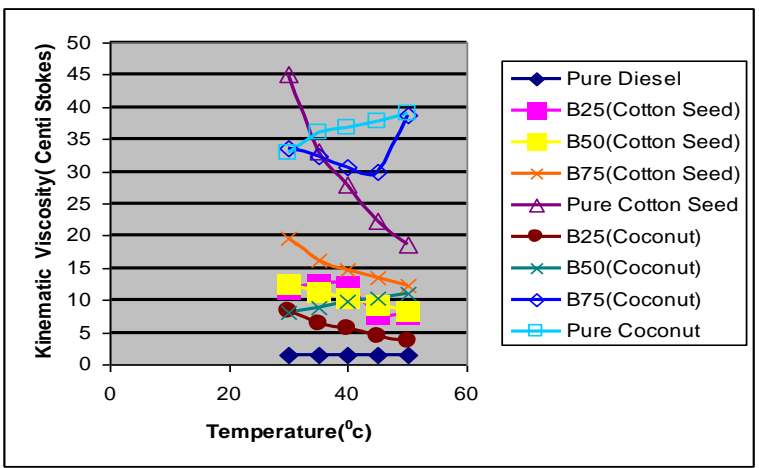

Fig. 5.2. Temperature Vs Kinematic Viscosity

The variation of kinematic viscosity with temperature for diesel and other fuels with Blends are shown in Fig. 5.2.As temperature increases, kinematic viscosity decrease and it is due to reduction in molecular attraction force. At all temperature pure coconut oil has more kinematic viscosity compared other fuels and different blends. 


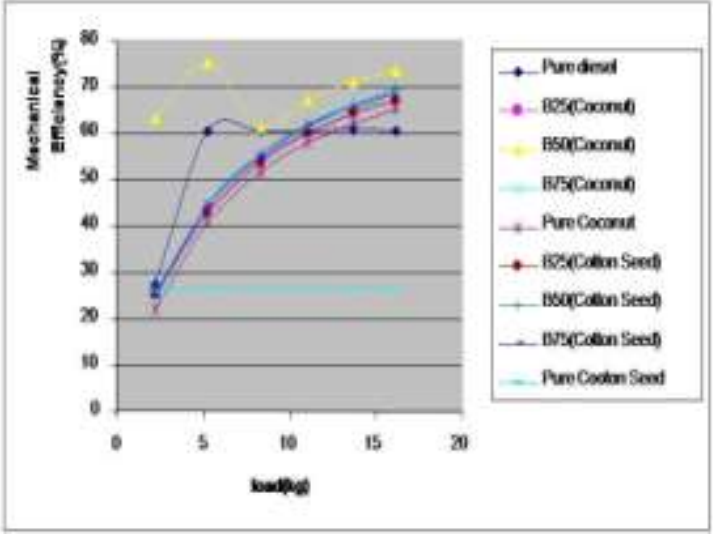

5.3 load Vs Mechanical Efficiency

Mechanical efficiency at various loads of the engine is shown in Fig. 5.3. It can be seen that for B50 (Coconut oil) at partial loads and maximum load Mechanical efficiency is higher than that of pure diesel and other fuels and blends. This may be due to better lubricating property of the oil, which reduces frictional losses.

\subsubsection{Volumetric Efficiency}

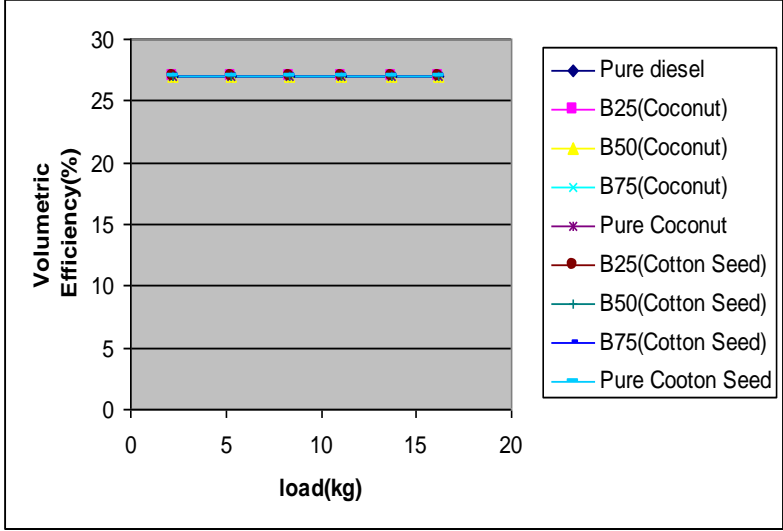

Fig. 5.4. Load Vs Volumetric Efficiency

Volumetric efficiency for various loads of the engine is shown in Fig. 5.4. It can be seen from graph that volumetric efficiency is almost constant when compared with all fuels and different blends at all loads of engine operation. The exact reason for this trend is to be analyzed more comprehensively.

\subsubsection{Brake Thermal Efficiency}

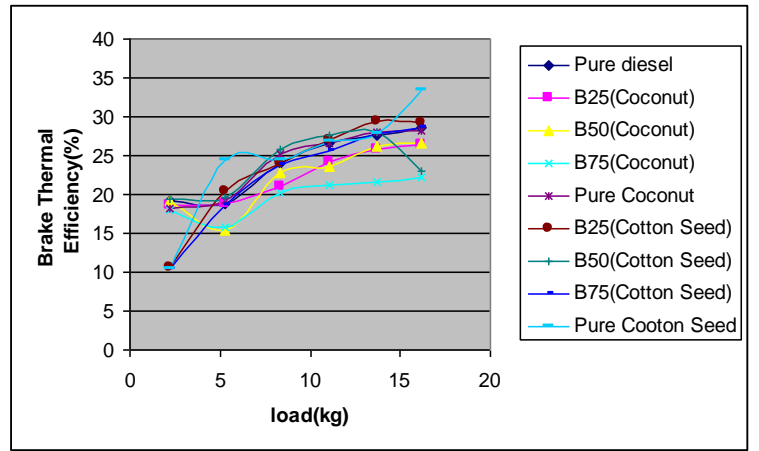

Fig. 5.5.Load Vs Brake Thermal Efficiency

Fig. 5.5 shows the variation of Brake thermal efficiency with variation of loads. It can be seen from graph that Brake thermal efficiency in all cases it increased with increased in load. This is due to reduction in heat loss and increase in power with increase in load. The maximum Brake thermal efficiency was obtained at pure 
cottonseed oil, which is higher than that of diesel and other blends. The improved brake thermal efficiency for lower concentration of cotton seed oil is due to more combustion and additional lubricities of oil.

\subsubsection{Indicated Thermal Efficiency}

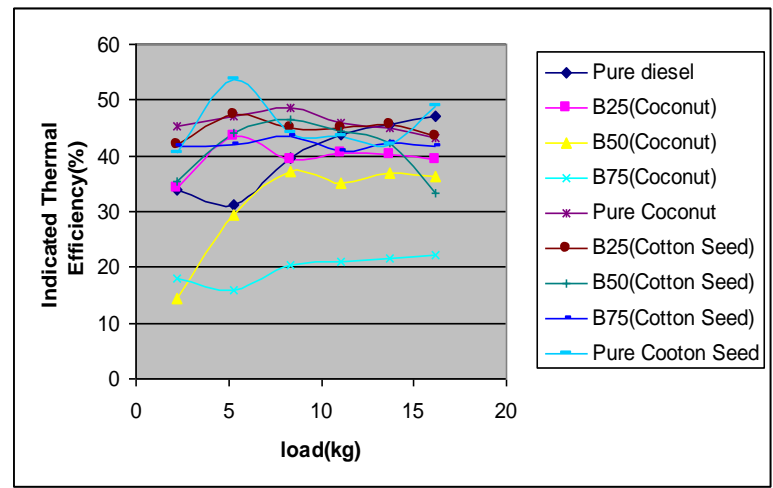

Fig. 5.6. Load Vs Indicated Thermal Efficiency

The variation of Indicated Thermal Efficiency with load for different fuels and blends is presented in Fig. 5.6. It can seen from graph that Indicated Thermal Efficiency is higher than that of pure cotton seed oil at maximum load to compare other fuels and different blends.

\subsection{Exhaust Emissions of Engine}

During continuous running of engine for given period of time, the exhaust gases such as $\mathrm{NO}_{\mathrm{X}}, \mathrm{CO}_{2}, \mathrm{CO}, \mathrm{O}_{2}$ and $\mathrm{HC}$ were studied and through which emission performance of the engine has been shown.

\subsubsection{Emission of Carbon Monoxide (CO)}

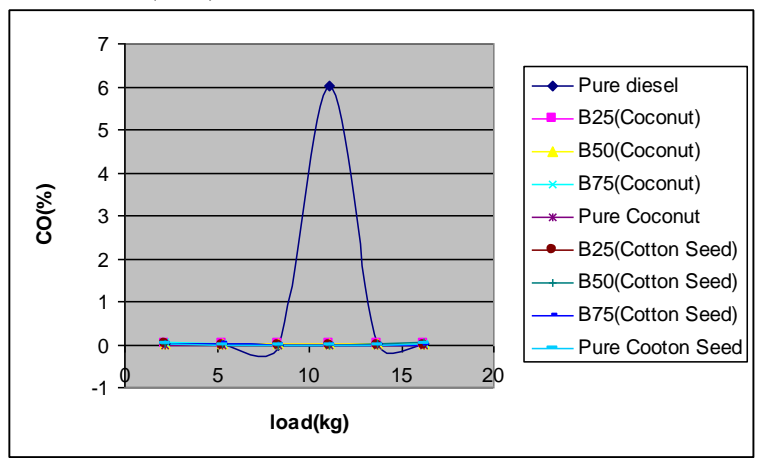

Fig. 5.7. Load Vs CO

The variation of CO produced by running the diesel engine using with different blends is compared with diesel as shown in Fig. 5.7. The minimum CO produced at pure coconut oil as compared to other blends and diesel. This is because of more complete combustion.

\subsubsection{Emission of Hydrocarbon(HC)}

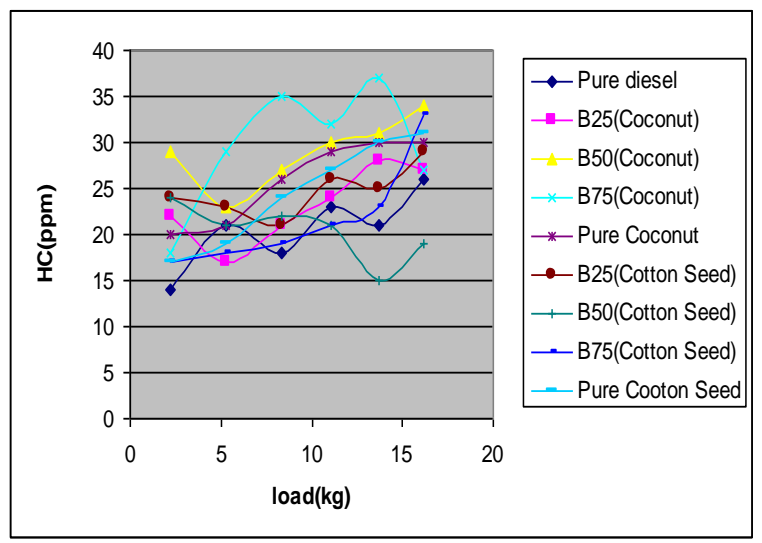

Fig. 5.8. Load Vs HC 
Variation of unburnt hydrocarbons for a various loads of fuels and blends as shown in Fig. 5.8. It can be seen that at maximum load for all blends of diesel with B50 (Cotton seed oil) emission is less when compared with other fuels and blends. This can be attributed to better and complete combustion of fuel blends when compared to other fuels and blends.

\subsubsection{Emission of Carbon Dioxide $\left(\mathrm{CO}_{2}\right)$}

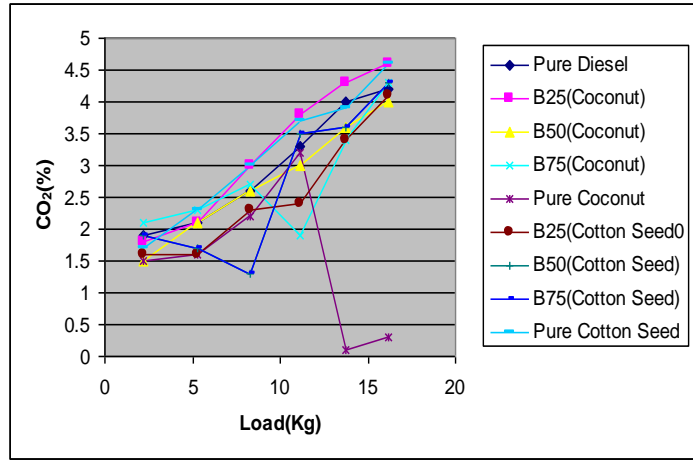

Fig. 5.9. Load Vs $\mathrm{CO}_{2}$

The variation of $\mathrm{CO}_{2}$ produced by running the diesel engine using with different blends is compared with diesel as shown in Fig. 5.9.The minimum $\mathrm{CO}_{2}$ produced at pure coconut oil as compared to other blends and diesel. This is because of more complete combustion.

\subsubsection{Oxygen $\left(\mathrm{O}_{2}\right)$}

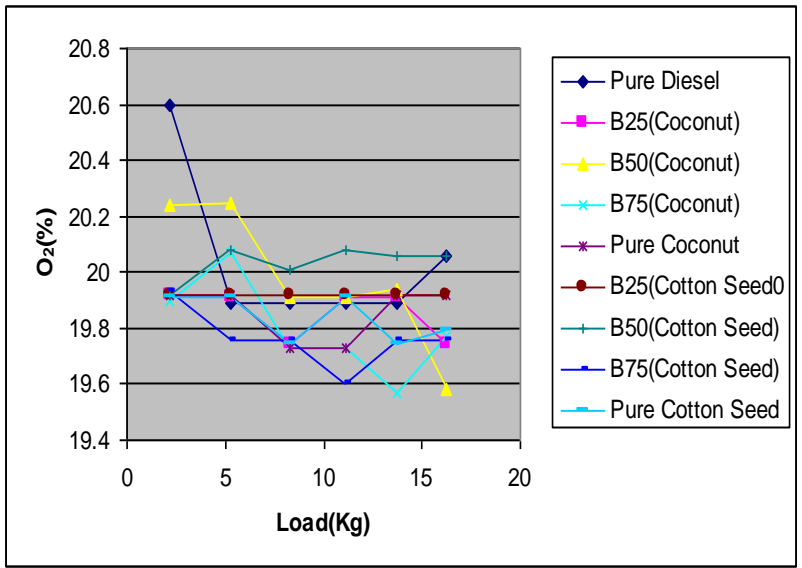

Fig. 5.10. Load $\mathrm{Vs}_{2}$

Variation of oxygen percentage for a various loads of fuels and blends as shown in Fig. 5.10. It can seen that B50 (Cotton seed oil) is more oxygenated fuel than that of all loads of fuels and other blends. This can be attributed to better and complete combustion of fuel blends when compared to other fuels and blends.

\subsubsection{Emission of Nitrogen Oxides $\left(\mathrm{NO}_{\mathbf{X}}\right)$}

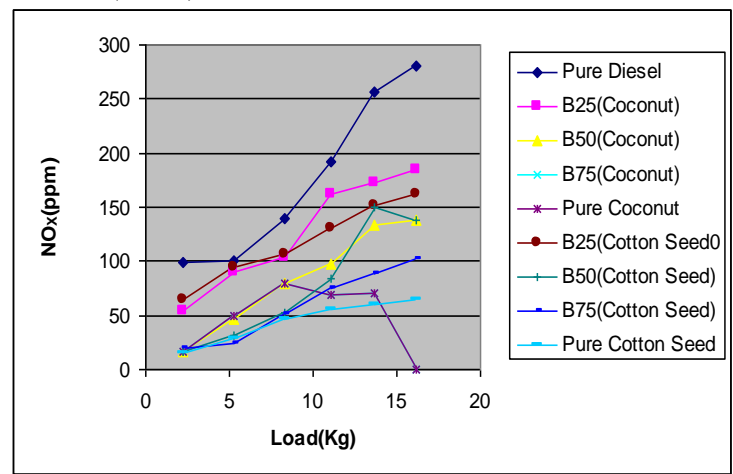

Fig. 5.11. Load $\mathrm{V}_{\mathrm{s}} \mathrm{NO}_{\mathrm{X}}$ 
Fig. 5.11 shows Nitrogen oxide emissions. The NOx emission is strongly related to lean fuel with high cylinder temperature or high peak combustion temperature. A fuel with high heat release rate at premix or rapid combustion phase and lower heat release rate at mixing will produce NOx emission. Variation NOx for a various loads of fuels and blends as shown in Graph-11. It can be seen that at maximum load for all blends of diesel with B50 (Cotton seed oil) emission is less when compared with other fuels and blends. This can be attributed to better and complete combustion of fuel blends when compared to other fuels and blends.

\subsubsection{Air Fuel Ratio}

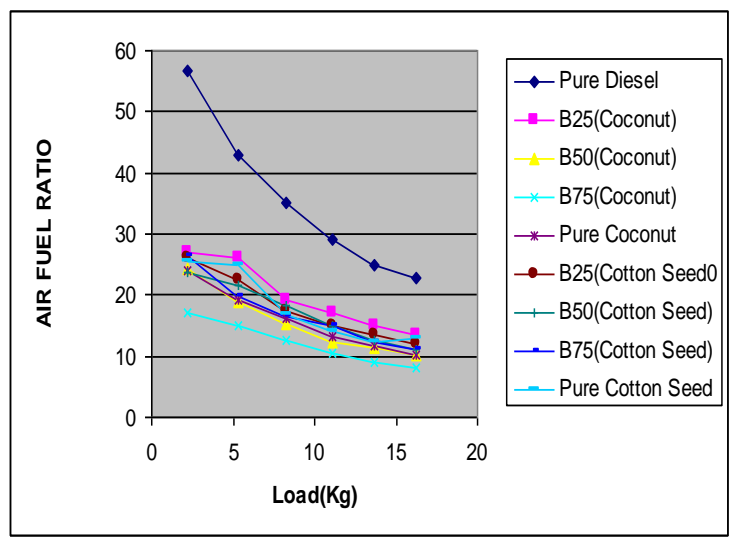

Fig. 5.12. Load Vs Air Fuel Ratio

Air fuel ratio for various loads of an engine operation with blends of fuel is shown in Fig. 5.12. B75 (Coconut oil) has low A/F ratio when compared with pure diesel and other blends for any load. This may be attributed to the fact that there is fuel bound hydrocarbons in the B75 (Coconut oil) because of which more air is needed than diesel for complete combustion of fuel and air.

\section{Scope of Future Work}

The past studies reveal that variety of vegetable oils is investigated in CI engines with little or no modification. The blends of vegetable oils with diesel, pure vegetable oils were tried and the performance and emissions of these engines are reported. Since vegetable oils have high viscosity and low volatility, these have shown poor performance in the conventional CI engines. Engine starting, nozzle clogging, increased smoke, piston seizure due to deposit formation, lubricating oil deterioration is the problems reported. All these problems are persisting even with use of esterifies oils in engines. Though the researchers have recommended the use of some of the vegetable oils in diesel engines there is no evidence of any practical oil engines. Considering the above, the future work is planned carefully. Tested various vegetable oils such as Cotton seed oil, Coconut oil in a single cylinder 4-stroke diesel engine. It is reported that Cotton seed oil performs better compared to other vegetable oil. However the results are not encouraging and as such the problems like starting ability, nozzle clogging, higher smoke levels, engine seizure due to deposit formations, lubricating oil degradation etc. are still persisting. The concept of use of vegetable oils in a single cylinder 4-stroke diesel engine is yet to be investigated thoroughly to develop a feasible vegetable oil based engine. Different levels of insulation are employed on a conventional CI engine as a first phase of the experimental work. It is planned to study the effects of various insulation levels and to identify the best method of insulation. In the best performed a single cylinder 4-stroke diesel engine, vegetable oils are tried to study the performance. For solving the problems associated with these oils, next phase of the work is planned with one of the oils which gives better performance.

\section{Conclusion:}

The experimental investigations on 4 stroke compression ignition engine by using the Diesel and alternative fuels like coconut oil and cotton seed oil are used as fuels. Previously efficiency of alternative fuels like coconut oil and cotton seed oil blends with diesel was tested. The blends of varying proportions of these alternative fuels and diesel are used to run the engine and significant improvements in engine performance and emission characteristics are observed. These improvements are attributed to more complete combustion of oxygenated fuel. Engine performance values such as Indicated Horse Power, Brake Horse Power, Fuel Consumption, Mechanical Efficiency, Volumetric Efficiency, Indicated Brake Thermal Efficiency and Air Fuel Ratios are determined by varying fuel injection pressure with variation of Engine loads along with different blends of oils. Even through the viscosity of the coconut oil is low and is economically friendly. Considering the thermal efficiency, the cotton seed oil blend (B50) is preferable as it is giving it is good characteristics curve. 
The performance characteristics are explained detailed in below:

$>$ Mechanical efficiency at various loads of the engine, It can be seen that for B50 (Coconut oil) at partial loads and maximum load Mechanical efficiency is higher than that of pure diesel and other fuels and blends. This may be due to better lubricating property of the oil, which reduces frictional losses.

$>$ Volumetric efficiency for various loads of the engine, It can be seen from graph that volumetric efficiency is almost constant when compared with all fuels and different blends at all loads of engine operation. The exact reason for this trend is to be analyzed more comprehensively.

$>$ The variation of Brake thermal efficiency with variation of loads. It can be seen from graph that Brake thermal efficiency in all cases it increased with increased in load. This is due to reduction in heat loss and increase in power with increase in load. The maximum Brake thermal efficiency was obtained at pure cottonseed oil, which is higher than that of diesel and other blends. The improved brake thermal efficiency for lower concentration of cotton seed oil is due to more combustion and additional lubricities of oil.

$>$ The variation of Indicated Thermal Efficiency with load for different fuels and blends is presented in Fig. 5.6. It can seen from graph that Indicated Thermal Efficiency is higher than that of pure cotton seed oil at maximum load to compare other fuels and different blends.

$>$ The variation of $\mathrm{CO}$ produced by running the diesel engine using with different blends is compared with diesel as shown in Fig. 5.7. The minimum CO produced at pure coconut oil as compared to other blends and diesel. This is because of more complete combustion.

$>$ Variation of unburnt hydrocarbons for a various loads of fuels and blends. It can be seen that at maximum load for all blends of diesel with B50 (Cotton seed oil) emission is less when compared with other fuels and blends. This can be attributed to better and complete combustion of fuel blends when compared to other fuels and blends.

$>$ The variation of $\mathrm{CO}_{2}$ produced by running the diesel engine using with different blends is compared with diesel. The minimum $\mathrm{CO}_{2}$ produced at pure coconut oil as compared to other blends and diesel. This is because of more complete combustion.

$>$ The NOx emission is strongly related to lean fuel with high cylinder temperature or high peak combustion temperature. A fuel with high heat release rate at premix or rapid combustion phase and lower heat release rate at mixing will produce NOx emission. Variation NOx for a various loads of fuels and blends as shown in Graph-11. It can be seen that at maximum load for all blends of diesel with B50 (Cotton seed oil) emission is less when compared with other fuels and blends. This can be attributed to better and complete combustion of fuel blends when compared to other fuels and blends.

\section{References:}

[1] Mr.S.V.Channapattana Dr.R.R.Kulkarni "Bio-diesel as a fuel in I.C. engines - A review", International Journal Of Computer Science And Applications Vol. 2, No. 1, April / May 2009 ISSN: 0974-1003.

[2] R. Ganapathi, Dr. B. Durga Prasad, B.Omprakash “ Performance Evaluation of a Low Heat Rejection Diesel Engine with Jatropha as Fuel", The International Journal Of Engineering And Science (IJES) || Volume || 2 || Issue || 11 || Pages || 01-06 || 2013 || ISSN (e): 2319 - 1813 ISSN (p): 2319 - 1805.

[3] Dhruva D,Dr. M C Math “ Investigation of Fuel Properties of Crude Rice Bran Oil Methyl Ester and Their Blends with Diesel and Kerosene", International Journal of Engineering Science Invention ISSN (Online): 2319 - 6734, ISSN (Print): 2319 - 6726 www.ijesi.org Volume 3 Issue 6\| June 2014 || PP.04-09.

[4] AlirezaValipour "Experimental Combustion Analysis of Biodiesel Fuel Spray with Hot Surface Ignition", IPASJ International Journal of Mechanical Engineering (IIJME), Volume 2, Issue 1, January 2014 ISSN 2321-6441.

[5] McGill, R., Storey, J., Wagner, R., Irick, D. et a, "Emission Performance of Selected Biodiesel Fuels," SAE Technical Paper 200301-1866, 2003, doi:10.4271/2003-01-1866.

[6] Postrioti, L., Battistoni, M., Grimaldi, C., and Millo, F., "Injection Strategies Tuning for the Use of Bio-Derived Fuels in a Common Rail HSDI Diesel Engine," SAE Technical Paper 2003-01-0768, 2003, doi:10.4271/2003-01-0768.

[7] Vellguth, G., "Performance of Vegetable Oils and their Monoesters as Fuels for Diesel Engines," SAE Technical Paper 831358, 1983, doi:10.4271/831358

[8] Yoshimoto, Y., Onodera, M., and Tamaki, H., "Reduction of Nox, Smoke, and BSFC in a Diesel Engine Fueled by Biodiesel Emulsion with Used Frying Oil," SAE Technical Paper 1999-01-3598, 1999, doi:10.4271/1999-01-3598. 